\title{
Remarks on the Theory of Relativity (1922)
}

\section{Henri Bergson}

Journal of French and Francophone Philosophy - Revue de la philosophie française et de langue française, Vol XXVIII, No 1 (2020) pp 167-172

\author{
Vol XXVIII, No 1 (2020) \\ ISSN 1936-6280 (print) \\ ISSN 2155-1162 (online) \\ DOI 10.5195/jffp.2020.904 \\ www.jffp.org
}

\section{(oc) $\overline{E Y-N C-N D}$}

This work is licensed under a Creative Commons Attribution-Noncommercial-No Derivative Works 3.0 United States License.

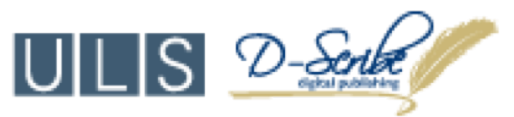

This journal is operated by the University Library System of the University of Pittsburgh as part of its D-Scribe Digital Publishing Program, and is co-sponsored by the University of Pittsburgh Press 


\section{Remarks on the Theory of Relativity (1922)}

\section{Henri Bergson}

Bergson: I came here to listen. It was never my intention to give a speech. But I yield to the amicable insistence of the Société de Philosophie.*

Let me begin by expressing the extent to which I admire the work of M. Einstein. It appears to me to demand the attention of philosophers as much as of scientists. I see in it not only a new physics, but also, in some ways, a new manner of thinking.

A complete in-depth study of this work should naturally deal with the theory of general relativity as well as that of special relativity, on the question of space as well as that of time. Since we must choose, I will take on the problem which especially interests me, that of time. And since we should not talk about time without taking into account the hour, and the hour is late, I will confine myself to some summary indications of one or two points. I will be forced to leave aside the essential.

Common sense believes in a single time, the same for all beings and all things. Where does this belief come from? Each of us feels that we endure; this duration is the very flow, continuous and undivided, of our inner life. But our inner life is composed of perceptions, and these perceptions seem all at once to be a part of ourselves and of things. We thus extend our duration to our immediate material surroundings. Moreover, as these surroundings are themselves surrounded, and thus goes on indefinitely, we think that there is no reason why our duration would not be the duration of all things as well. This is the reasoning that each of us sketches out vaguely, I would almost say, unconsciously. When we bring it to a higher degree of clarity and precision, we represent to ourselves, beyond what might be called the horizon of our external perception, a consciousness whose field of perception would encroach on ours, then, beyond this consciousness and its field of perception, another consciousness situated in an analogous manner, and so on, indefinitely. All these consciousnesses being human consciousnesses, we appear to live in the same duration. All their external experiences would 
unfold in the same time. And as all these experiences, encroaching on one another, have something in common, we end up representing to ourselves a single experience, occupying a single time. Thereafter we can, if we wish, eliminate the human consciousnesses that we had arranged at distant intervals as so many relays for the movement of our thought; there is nothing more than the impersonal time in which all things flow. Here is the same reasoning in a more precise form. Moreover, whether we remain in vagueness or seek precision, in both cases the idea of a universal time, common to consciousnesses and things, is a mere hypothesis.

But it is a hypothesis that I believe to be well-founded, and which, to my way of thinking, is not incompatible with the theory of relativity. I cannot undertake the demonstration of this point. It would first be necessary to study real duration and measurable time much more minutely than I just did. Then, we would have to take the terms which enter into Lorenz's formulas one by one and seek out their concrete significance. We would then find that the multiple times at issue in the theory of relativity are far from being able to claim the same degree of reality. As we advanced in this study, we would see how the relativist conception, which corresponds with the point of view of science, and the conception of common sense, which roughly translates the data of intuition or consciousness, complement each other and lend mutual support. It is true that, on the way, it would be necessary to dispel a very serious confusion, to which certain commonly accepted interpretations of the relativist theory owe their paradoxical form. All this would lead us too far afield.

But what I cannot establish for time in general, I ask your permission to offer at least a glimpse for the particular case of simultaneity. Here we will easily see that the relativist point of view does not exclude the intuitive point of view, and even necessarily implies it.

What do we ordinarily mean by the simultaneity of two events? I will consider, for simplicity, the case of two events that would not endure, that would not themselves be in flux. Positing this, it is evident that simultaneity implies two things: 1 . An instantaneous perception; 2 . The possibility for our attention to be shared without being divided [se partager sans se diviser]. I open my eyes for a moment: I perceive two instantaneous flashes starting from two points. I call them simultaneous because they are one and two all at once: one as my act of attention is indivisible, two as my attention is nevertheless divided [se répartit] between them and is split [se dédouble] without being split apart [se scinder]. How can the act of attention be one or many depending on my will, all in one stroke and all at once? How does a trained ear perceive at each instant the total sound made by the orchestra and yet, if it pleases, untangle the notes played by two or more instruments? I do not take it upon myself to explain it; it is one of the mysteries of psychological life. I simply observe this and remark that by declaring simultaneous the notes played by several instruments, we express: 1 . That we have an instantaneous perception 
of the whole; 2 . That this whole, indivisible if we want, is also divisible if we want. There is a single perception, and nevertheless there are many. Such is simultaneity, in the commonly accepted sense of the word. It is given intuitively. And it is absolute in the sense that it does not depend on any mathematical convention, on any physical operation such as the setting of a clock. It is never observable, I recognize, except between neighboring events. But common sense does not hesitate to extend it to events as remote from one another as one would want. It says, instinctively, that distance is not an absolute, that it is "great" or "small" according to the point of view, according to the term of comparison, according to the instrument or organ of perception. A superhuman with giant vision would perceive the simultaneity of two "enormously remote" instantaneous events as we perceive the simulataneity of two "neighboring" events. When we speak of absolute simultaneities, when we represent to ourselves instantaneous sections of the universe, which would gather, so to speak, definitive simultaneities between events as distant from one another as one would want, it is of this superhuman consciousness, coextensive with the totality of things, that we think.

Now, it is undeniable that the simultaneity defined by the theory of relativity is of a completely different order. Here, two more or less distant events, belonging to the same system $S$, are said to be simultaneous when they occur at the same time, when they correspond to the same reading given by two clocks which are found beside each of them respectively. For these clocks have been adjusted to each other by an exchange of optical, or more generally, electromagnetic, signals, on the hypothesis that the signal took the same path out and back. And this is the case, without any doubt, if one places oneself at the point of view of an observer who is internal to the system and takes it to be immobile. But the observer who is internal to another system $S^{\prime}$, which is in motion in relation to $S$, takes his own system as a frame of reference, considers it to be immobile, and views the first as in motion. For this observer, the signals that come and go between two clocks from system $S$ do not, in general, take the same path out and back; and consequently, for this observer, the events that occur in this system when the two clocks mark the same time are not simultaneous, they are successive. If we grasp simultaneity in this way-and this is what the theory of relativity does-it is clear that simultaneity is nothing absolute, and that the same events are simultaneous or successive depending on the point of view from which one considers them.

But, in positing this second definition of simultaneity, are we not obliged to accept the first? Do we not implicitly admit this one alongside the other? Let us call the two events that are compared $\mathrm{E}$ and $\mathrm{E}^{\prime}$, and the clocks placed

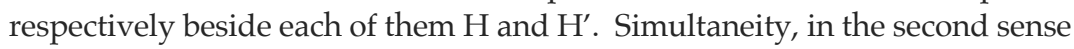
of the word, exists when $\mathrm{H}$ and $\mathrm{H}^{\prime}$ mark the same time; and this is relative, because it depends on the operation by which these two clocks have been adjusted to each other. But, if indeed this is simultaneity between the readings of the clocks $\mathrm{H}$ and $\mathrm{H}^{\prime}$, is it likewise simultaneity between the reading of clock 
$\mathrm{H}$ and event $\mathrm{E}$, between the reading of clock $\mathrm{H}^{\prime}$ and event $\mathrm{E}^{\prime}$ ? Obviously not. The simultaneity between the event and the clock's reading is given by the perception that unites them in an indivisible act. It essentially consists of the fact-independent of all setting of the clocks-that this act is one or two, depending on our will. If this simultaneity did not exist, the clocks would serve no purpose. We would not manufacture them, or at least no one would buy them. For one only buys a clock in order to know what time it is; and "knowing what time it is" consists in observing a correspondence, not between one clock's reading and another clock's reading, but between a clock's reading and the moment in which we find ourselves, the event that is occurring, something that is ultimately not a reading of the clock.

You will tell me that the intuitively observed simultaneity between some event or other and this particular event that is a clock's reading is a simultaneity between neighboring events, very close neighbors, and that the simultaneity with which you generally occupy yourself is that of events remote from each other. But, once again, where does the proximity begin and the remoteness end? Intelligent microbes, situated respectively at points $\mathrm{E}$ and $\mathrm{H}$, would find the distance that separates them enormous, that is to say, the distance between the clock and the event you declare "neighboring." They would build microbial clocks which they would synchronize by an exchange of optical signals. And when you would come to tell them that your eye purely and simply observes a simultaneity between event $\mathrm{E}$ and clock reading $\mathrm{H}$, which is "neighboring," they would answer you: "Oh no! We do not admit that. We are more Einsteinian than you, Mr. Einstein. There will only be simultaneity between the event $\mathrm{E}$ and the reading of your human clock $\mathrm{H}$, if our microbial clocks, placed at $\mathrm{E}$ and $\mathrm{H}$, mark the same time; and for an observer external to our system, this simultaneity will be succession, it will have nothing intuitive or absolute."

I have no objection to your definition of simultaneity, any more than I have against the theory of relativity in general. The observations I have just presented (or rather sketched, for I would be led very far afield if I wanted to give them a rigorous form) have a completely different objective. What I want to establish is simply this: once the theory of relativity is admitted as a physical theory, all is not finished. We still have to determine the philosophical significance of the concepts it introduces. We still have to seek to what extent the theory renounces intuition and to what extent it remains attached to intuition. We still have to distinguish between the real and the conventional in the results it achieves, or rather the intermediaries it establishes between the posing of the problem and its solution. In doing this work concerning time, we become aware, I believe, that the theory of relativity has nothing incompatible with the ideas of common sense.

Einstein: The question therefore arises: Is the time of the philosopher the same as that of the physicist? The time of the philosopher, I believe, is at once a psychological and a physical time. Now, physical time can be derived from 
the time of consciousness. Primordially, individuals have the notion of the simultaneity of perception. They can thereby understand each other and agree on something they perceived. That was a first step toward objective reality. But there are objective events, independent of individuals, and from the simultaneity of perceptions we have passed on to the simultaneity of events themselves. And, in fact, for a long time this simultaneity did not lead to any contradiction because of the high speed propogation of light. The concept of simultaneity could thus pass from perception to objects. From there, it was not far to deduce a temporal order of events, and instinct did it. But nothing in our consciousness allows us to conclude the simultaneity of the events, for these are only mental constructions, logical beings. Thus, there is no time of the philosopher; there is only a psychological time different from the time of the physicist.

M. Piéron: With respect to the confrontation between psychological duration and Einsteinian time attempted by M. Bergson, I would like to point out that there are some places where this confrontation is realized experimentally, when the psycho-physiologist studies, by means of a scientific method, the impressions of duration, succession, and simultaneity.

Now, for quite a long time, astronomers have already recognized that it was impossible to rely on psychological simultaneity to determine a physical simultaneity with precision when it was a matter of using the method of the eye and the ear to specify the position of a star in the reticle of a telescope at the moment of the beat of a pendulum. Here, indeed, is the type of concrete experience pointed out by Mr. Bergson to show the possible intervention of impressions of duration in determinations relative to physical time.

Now, we know that it is physiologically impossible to obtain an exact mental translation of a physical simultaneity between heterogeneous sensory impressions. Indeed, both the latency of transformation of the external stimulus into nerve impulses and the time of propagation of this influx change with the regions of the body and the sense organs involved, taking no account of the complex and irregular cerebral variations. But there is more: suppose that two symmetrical points of the retina perceive a visual impression; it seems that, under these conditions, the perceived simultaneity will be a sure sign, within the limits of a given approximation, of physical simultaneity. However, it is enough that the visual impressions have a different intensity for it not to be the case. I have been able to measure a difference in intensities where the weaker visual stimulus, which physically precedes the stronger by a few hundredths of a second, is actually perceived clearly as later. Thus, determinations of psychological succession or simultaneity cannot in any case 
be utilized in measuring physical time, which requires a spatial translation, according to a scientific rule that has been rightly brought to light by $\mathrm{Mr}$. Bergson. It is by the coincidence or non-coincidence of traces left by some signaling device on a surface animated by a more or less rapid movement that we judge the physical simultaneity, taking into account all the necessary corrections. For these measurements of time, as for all others, it is visual acuity which intervenes. And thus it appears to me that Bergsonian duration must remain foreign to physical time in general and particularly Einsteinian time.

Bergson: I am entirely in agreement with Mr. Piéron: the psychological observation of a simultaneity is necessarily imprecise. But, in order to establish this point by laboratory experiments, it is to psychological observations of simultaneities-however imprecise-that we must resort; without them, no reading of the device would be possible.

Translated by Heath Massey

* This is an excerpt of a discussion that took place at the April 6, 1922 meeting of the Societé française de Philosophie, which featured Albert Einstein as a guest speaker. I am grateful to the Société française de philosophie for permission to publish this translation. The full discussion was originally published as "La Théorie de la relativité: séance du 6 avril 1922," Bulletin de la société française de philosophie 22, no. 3 (July 1922): 102-113 (https://www.sofrphilo.fr/la-theorie-de-la-relativite/). The original version can be accessed on the Société française de philosophie's "Major Conferences" webpage at https://www.sofrphilo.fr/activites-scientifiques-de-lasfp/conferences/grandes-conferences-en-telechargement/. This excerpt was published later as Henri Bergson, "Remarques sur la théorie de la relativité," in Écrits et paroles Vol. 3, ed. R. M. Mossé-Bastide (Paris: Presses Universitaires de France, 1959), 497-503 and as "Discussion avec Einstein" in Mélanges, ed. André Robinet (Paris: Presses Universitaires de France, 1972), 1340-1347. The excerpt appears in translation in P. A. Y. Gunter, Bergson and the Evolution of Physics (Knoxville: University of Tennessee Press, 1969), 128-135. Bergson's remarks and Einstein's brief reply are one of the focal points of a recent work examining the two thinkers: Jimena Canales, The Physicist and the Philosopher: Einstein, Bergson, and the Debate that Changed Our Understanding of Time (Princeton: Princeton University Press, 2015). 